\title{
FAMILIRIZATION TRIP OLEH DINAS PARIWISATA DAN KEBUDAYAAN DKI JAKARTA DALAM PENGENALAN MUSEUM TEKSTIL TERHADAP WISATAWAN MANCANEGARA
}

\author{
Sylvia Desianty \\ ${ }^{1}$ Fakultas Ilmu Komunikasi, London School of Public Relation \\ syldesianty@gmail.com
}

\begin{abstract}
Abstrak
Penelitian ini bertujuan untuk menganalisa bagaimana strategi Familirization Trip (Famtrip) dilakukan, hasil dari strategi Famtrip dan juga hambatan yang terjadi di dalam Famtrip tersebut. Metode yang digunakan dalam penelitian ini adalah deskriptif kualitatif dengan menggunakan Nine Steps of Public Relations oleh Ronald D. Smith untuk menganalisa strategi dan wawancara dan juga analisis data dalam menemukan hasil dan hambatan. Hasil dari penelitian ini adalah selama Famtrip ini sudah berhasil dilaksanakan dengan baik namun belum memberikan dampak yang signifikan terhadap peningkatan wisatawan mancanegara ke Museum Tekstil Jakarta karena terdapat hambatan dalam perencanaan, pelaksanaan, hingga pelaporan. Oleh karena itu, penelitian ini diharapkan dapat menjadi bahan evaluasi bagi Dinas Pariwisata dan Kebudayaan DKI Jakarta dalam memperkenalkan Musem Tekstil Jakarta kepada wisatawan mancanegara.
\end{abstract}

Kata kunci : Wisata, Familirization Trip, Museum Tekstil Jakarta, Strategi.

\begin{abstract}
This research is conducted to analyze how the Famtrip strategy is done, the result, and the obstacle. The method used in this research is descriptive qualitative using the Nine Steps of Public Relations by Ronald D. Smith to analys the strategy, interview and data research to analys the result and the obstacle. The result of this research explains that Famtrip has been done well but in the other hand has not give significant result to the increasing number of foreign tourists visiting Jakarta Textile Museum.
\end{abstract}

Keywords: Tourism, Familiarization Trip, Museum Tekstil Jakarta, Strategy.

\section{Pendahuluan}

Jakarta sebagai Ibukota Negara Republik Indonesia memiliki dayatarik tersendiri bagi wisatawan mancanegara. Daya tarik ini tentunya harus ditunjang dan didukung dengan berbagai sarana dan prasarana yang turut menunjang agar dapat memenuhi standar international sebagai sebuah Ibukota Negara yang siap bersaing dengan kota-kota di Negara lain sebagai salah satu daerah tujuan wisatadunia.

Dengan kekayaan sejarah dari beragam ras dan etnis, ibukota Indonesia, Jakarta, telah menyatukan berbagai kepentingan dan jaringan nasional maupun internasional, menyediakan pembelajaran dari masa lalu dan kreasi, inovasi, dan harapan bagi generasi masa datang (Jakarta Tourism, 2015). Hal ini menyebabkan Jakarta sangat kaya dengan sejarah dan budaya. Oleh karena itu, penting untuk melestarikan kebudayaan dan juga mengenalkan pariwisata sejarah Jakarta.

Salah satu potensi pariwisata di Jakarta yang kental dengan kebudayaan dan sejarahnya adalah Museum Tekstil Jakarta. Museum Tektstil Jakarta didirikan pada tahun 1976 dipelopori oleh Gubernur Jakarta pada saat itu, Bapa Ali Sadikin dengan tujuan untuk menghormati Ibu Negara, Ibu Tien Soeharto dan diresmikan pada tanggal 18 Juni 1976. Pada pertengahan era 1970, penggunaan tekstil, serta jumla dan mutu produksi sangat menurut. Beberapa jenis tekstil bahkan sangat langka. Hal ini kemudian memotivasi beberapa warga untuk mendirikan lembaga yang didedikasikan untuk pelestarian dan penelitian tekstil Indonesia. Pemerintah Provinsi menyediakan akomodasi berupa sebuah bangunan tua yang indah di daerah Tanah Abang Jakarta (Museum Tekstil Jakarta, 2013).

Pada tahun 1062, property ini diakuisisi oleh Departemen Sosial untuk digunakan sebagai kantor, kemudian secara resmi bangunan dan tanahnya diserahkan kepada Pemerintah DKI Jakarta dan Gubernur Ali Sadikinmemutuskan bahwa kebutuhan untuk melestarikan tradisi tekstil di Indonesia lebih besar dari kebutuhan kota untuk menyimpan arsip, oleh karena itu, lahirlah Museum Tekstil (Museum Tekstil Jakarta, 2013). 
Jurnal Teknologi Informasi dan Komunikasi, ISSN : 2087-0868, Volume 11, Nomor 2, September 2020 , FAMILIRISATION TRIP OLEH DINAS PARIWISATA DAN KEBUDAYAAN DKI JAKARTA DALAM PENGENALAN MUSEUM TEKSTIK TERHADAP WISATA MANCANEGARA

Museum Teksil Jakarta memiliki beberapa fasilitas diantaranya adalah Main Building, Batik Gallerry, The Batik Pavilion, Natural Dye Garden, Library, Laboratory Storage, Gift Shop, Auditorium, Praying Room, Internet Hotstpot, Fiber Gardern, Introduction to Wastra Room, Mini Theater, Parking Space (Museum Tekstil Jakarta, 2013).

Museum Teksil merupakan salah satu destinasi wisata di Jakarta yang masih memiliki nuansa sejarah. Selain dari fungsinya yaitu untuk membudidayakan tekstil di Indoensia, bangunan Museum Tekstil juga masih kental dengan Jakarta tempo dulu dengan design Belanda yang masih kental. Selain itu, Museum Tekstil juga memberikan pengalaman yang berbeda. Tidak hanya pengunjung bisa melihat tekstil di Indonesia dan peralatan untuk membuatnya, tapi pengunjung juga bisa mencoba mengoperasikan alat yang digunakan untuk memproses bahan baku, hingga belajar untuk membuat batik mereka sendiri (Museum Tekstil Jakarta, 2013).

Keunggulan dari Museum Teskstil jika dibandingkan dengan Museum lain adalah workshop batik. Pengunjung bisa belajar cara membuat batik dan membawa hasil karya mereka untuk dibawa pulang.

Salah satu usaha yang dilakukan oleh Dinas Pariwisata dan Kebudayaan DKI Jakarta dalam memperkenalkan Museum Tekstil dikalangan wisatawan mancanegara adalah Familiarization Trip, atau Famtrip.

Famtrip merupakan sebuah perjalanan seseorang atau sekelompok orang yang merupakan ikon di masyarakat seperti tokoh, artis, public figure atau lainnya dengan tujuan untuk mengenalkan obyek-obyek wisata (Kurniardi, 2015). Peraturan Menparekraf No. 5 Tahun 2013 menyatakan bahwa Famtrip merupakan kegiatan membawa orang atau sekelompok orang, berdasarkan program tertentu untuk mengunjungi daya tarik wisata dalam rangka pengenalan dan/atau promosi pariwisata. Kegiatan Famtrip diharapkan mampu memberikan kontribusi dalam menarik minat wistawan. Dalam pelaksanaan kegiatan Famtrip, tujuannya adalah menciptakan awareness akibat pengalaman yang dirasakan selama perjalanan (Jaringan Dokumentasi dan Informasi Hukum Biro Hukum dan Kepegawaian Sekretariant Jenderal, 2013, p.251).

Kegiatan Famtrip merupakan strategi yang digunakan untuk memperkenalkan destinasi dan produk wisata Indonesia melalui media atau perjalanan langsung. Diharapkan dapat terjalin hubungan kerjasama yang baik antar negara, serta persaingan yang sehat dalam dunia pariwisata.

Famtrip memiliki beberapa keunggulan karena mengeluarkan biaya yang lebih sedikit dibandingkan dengan pemasangan iklan di luar negeri dan media. Selain itu, mereka juga bisa langsung merasakan pengalaman mengunjungi obyek wisata di Indonesia (Prakoso, 2017).

Berdasarkan latar belakang diatas, maka peneliti memutuskan untuk menganalisis tentang strategi Familiarization Trip yang dilakukan oleh Dinas Pariwisata dan Kebudayaan DKI Jakarta dalam memperkenalkan Museum Tekstil Jakarta kepada wisatawan mancanegara sehingga dapat diketahui tentang bagaimana strategi yang dilakukan, hasil, serta hambatan sehingga dapatdiperbaiki menjadi lebih baik lagi agar dapat mempromosikan pariwisata yang ada di DKI Jakarta

\section{Metode Penelitian}

Menurut (Ardianto, 2014, p.59) dalam bukunya Metode Penelitian untuk Public Relations menuliskah bahwa penelitian kualitatif berasal dari ilmu-ilmu perilaku dan ilmu-ilmu sosial. Penelitian Kualitatif memiliki esensi sebagai sebuah metode pemahaman atas keunikan, dinamika, dan hakikat holistik dari kehadiran manusia dan interaksinya dengan lingkungan.

Dalam buku Moleong dijelaskan tentang definisi-definisi kualitatif dan dapat disimpulkan bahwa penelitian kualitatif merupakan penelitian yang dimaksudkan untuk memahami fenomena yang dialami oleh subjek penelitian seperti prilaku, persepsi, motivasi, dan tindakan (Lexy J. Moleong, 2019, p.6)

Oleh karena itu, metode pendekatan yang akan digunakan dalam penelitian ini adalah pendekatan deskriptif. Menurut (Kriyantono, 2006, p.69). Kriyantono menyampaikan bahwa jenis riset deskriptif bertujuan untuk membuat deskripsi secara sistematis, factual, dan akurat tentang fakta-fakta dan sifat- sifat populasi atau objektertentu.

Penelitian ini didasari oleh rumusan-rumusan yang ada dalam menganalisis strategi yang digunakan oleh Dinas Pariwisata dan Kebudayaan DKI Jakarta dalam memperkenalkan Museum Teksil di Kalangan Wisatawan Mancanegara melalui Familiarization Trip dimana peneliti akan melakukan tanya jawab (interview) untuk lebih 
Jurnal Teknologi Informasi dan Komunikasi, ISSN : 2087-0868, Volume 11, Nomor 2, September 2020 , FAMILIRISATION TRIP OLEH DINAS PARIWISATA DAN KEBUDAYAAN DKI JAKARTA DALAM PENGENALAN MUSEUM TEKSTIK TERHADAP WISATA MANCANEGARA

memahami permasalahan dan untuk mengetahui jawaban dari fokus penelitian ini, juga melakukan observasi ke lapangan dan meneliti data. Pengumpulan data yang dilakukan menggunakan teknik wawancara dan dokumentasi yang akan didapatkan melalui narasumber maupun data berupahardcopy.

\section{Hasil dan Pembahasan}

\subsection{Hasil Dari Strategi Familiarization Trip oleh Dinas Pariwisata dan Kebudayaan DKI Jakarta dalam memperkenalkan museumTekstil kepada Wisatawan Mancanegara}

Program Famtrip yang dilakukan oleh

Dinas Pariwisata dan Kebudayaan DKI Jakarta sendiri berjumlah sebanyak 12 kali sedangkan 2 sisanya merupakan hasil kerjasama dengan Kementerian Pariwisata.

Perbedaanya Program Famtrip yang diadakan oleh Dinas Pariwisata dan Kebudayaan DKI Jakarta sendiri dengan bekerjasama dengan Kementerian Pariwisata adalah tempat kunjungannya. Famtrip yang diadakan oleh Kementerian Pariwisata mengunjungi beberapa kota di Indonesia. Sedangkan Famtrip yang diadakan oleh Dinas Pariwisata dan Kebudayaan DKI Jakarta hanya berkunjung ke Jakarta.

Data yang didapatkan dari Museum Tekstil menunjukkan bahwa jumlah wisatawan mancanegara yang datang ke Museum Tekstil berjumlah total 2,185 dengan 2,122 dewasa dan 63 mahasiswa asing orang pada tahun 2017. SD Seperti yang dikatakan oleh Sherly Yulita dalam wawancara peneliti, Famtrip yang diadakan dioleh Dinas Pariwisata dan Kebudayaan DKI Jakarta diadakan sejak tahun 2011, oleh karena itu, untuk menganalisa bahagimana hasil dari Familiarization Trip untuk memperkenalkan Museum Tekstil, data mengenai jumlah penduduk yang datang ke Museum Tekstil dari tahun 2011 adalah sebagaiberikut:

Tabel. 1 Jumlah Pengunjung Wisman Ke Museum Tekstil

\begin{tabular}{|l|l|l|l|l}
\hline Th & Dewasa & Mahasiswa & Grup & Jml \\
\hline 2010 & 559 & 15 & 100 & 674 \\
\hline 2011 & 838 & 164 & 757 & 1,759 \\
\hline 2012 & 1,174 & 0 & 0 & 0 \\
\hline 2013 & 1,075 & 0 & 196 & 1,271 \\
\hline 2014 & 874 & 0 & 0 & 874 \\
\hline 2015 & 1,735 & 0 & 0 & 1,735 \\
\hline 2016 & 758 & 0 & 0 & 758 \\
\hline
\end{tabular}

\begin{tabular}{l|l|l|l|l|}
2017 & 2,122 & 63 & 0 & 2,185 \\
\hline
\end{tabular}

Sumber : Data Olahan peneliti, 2018.

Hasil wawancara dengan Yeni, selaku Instruktur Batik di Museum Tekstil Jakarta dari tahun 2006, menunjukkan bahwa Yeni mengatakan bahwa pengunjung yang datang ke Museum Tekstil Jakarta bagaimanapun tetap didominasi oleh orang lokal.

Banyak orang lokal yang datang berkunjung, terutama saat ada kegiatan field trip dari sekolah. Untuk pelatihan membuat batik sendiri, hal itu sangat diminati oleh pengunjung lokal maupun internasional.

Yeni mengatakan bahwa, "Kalau untuk pengunjung pasti banyak orang kita. Belajar seperti mba tadi itu. Tapi yang lebih banyak bikin batik intensif itu kebanyakan orang asing. Kebanyakan orang Jepang sih bukan orang asing" (Yeni, wawancara data primer, 2 Juli2018).

Dari pernyataan diatas dijelaskan bahwa dalam belajar dan menggambar batik, setiap orang baik wisatawan lokal maupun mancanegara memiliki ketertarikan untuk mempelajari cara membuat batik. Namun, orang Jepang banyak yang mengikuti kelas intensil. Menurut Yeni hal ini dikarenakan perbedaan aktivitas.

Orang lokal banyak yang ingin belajar menggambar batik lebih dalam tapi tidak memiliki waktu dikarekana ada kesibukan lain seperti bekerja. Sedangkan orang Jepang yang sering datang untuk belajar membuat batik secara intensif adalah mereka yang menikah dengan orang Indonesia dan tinggal di Indonesia sehingga mereka tidak memiliki kegiatan lain selain menjadi ibu rumah tangga. Akhirnya mereka senang datang ke Museum Tekstil Jakarta untuk mempelajari cara membuat batik.

Untuk Famtrip, Yeni mengaku tidak begitu tahu tentang Famtrip. Beliau beberapa kali melihat kedatangan Abang None bersama tamu Famtrip, namun tidak begitu peduli tentang latar belakang kedatangannya, apakah dari Famtrip atau bukan.

Selain bekerjasama melalui program Famtrip, Museum Tekstil Jakarta juga bekerjasama dengan Dinas Pariwisata dan Kebudayaan DKI Jakarta dalam acara promo ke Luar Negeri lainnya seperti event dan pameran. Biasanya dalam pameran, Yeni menceritakan bahwa Dinas akan memamerkan tentang pariwisata DKI Jakarta dan Kebudayaan Betawi. Selain itu, Dinas Pariwisata 
Jurnal Teknologi Informasi dan Komunikasi, ISSN : 2087-0868, Volume 11, Nomor 2, September 2020 , FAMILIRISATION TRIP OLEH DINAS PARIWISATA DAN KEBUDAYAAN DKI JAKARTA DALAM PENGENALAN MUSEUM TEKSTIK TERHADAP WISATA MANCANEGARA

akan menyediakan atraksi dari Museum Tekstil Jakarta, yaitu belajar membuat batik scaragratis.

Hal ini menunjukkan bahwa banyak orang yang memiliki ketertarikan untuk belajar membatik. Meskipun saat pameran, para pengunjung tidak bisa melakukan proses pelepasan lilin dan hanya mewarnai menggunakan kuas.

Berdasarkan hasil penelitian di atas, peneliti kemudian membandingkan sarana Famtrip dengan pameran yang dilakukan oleh Dinas Pariwisata dan Kebudayaan DKI Jakarta dalam memperkenalkan dan meningkatkan jumlah kunjungan wisatawan mancanegara ke MuseumTekstil Jakarta. Peneliti mengambil kesimpulan bahwa untuk mengenalkan Museum Tekstil Jakarta, pameran lebih cocok diimplementasikan, karena informasi bisa disebarkan kepada pengunjung yang datang melalui anjungan DKI. Sedangkan jika melalui Famtrip, seperti data yang dijabarkan diatas, bahwa tidak semua peserta Famtrip di bawa untuk berkunjung ke Museum Teksil Jakarta dan tidak semua peserta Famtrip yang sudah di bawa ke Museum Tesksil Jakarta akan menulis tentang Museum Teksil Jakarta. Sehingga informasi mengenai Museum Teskil Jakarta tidak tersampaikan kepada si penerima pesan, karena pesan terhenti di medium atau penghantarpesan.

Peneliti kemudian mengolah dan meneliti data yang dapatkan dari bagian Informasi dan Pengembangan Dinas Pariwisata dan Kebudayaan DKI dan mendapatkan data sebagai berikut.

Berdasarkan data Kunjungan Wisatawan Mancanegara ke DKI Jakarta Berdasarkan Kebangsaan Tahun 2010-2017 yang diperoleh peneliti melalui Informasi dan Pengembangan Dinas Pariwisata dan Kebudayaan Jakarta, terjadi peningkatan pengunjung ke Jakarta seperti tertera pada tabel tersebut.

Tabel 2. Jumlah Wisatawan Mancanegara di Indonesia

\begin{tabular}{|l|l|}
\hline 2010 & 1.892 .866 \\
\hline 2011 & 2.003 .944 \\
\hline 2012 & 2.125 .513 \\
\hline 2013 & 2.313 .742 \\
\hline 2014 & 2.319 .295 \\
\hline
\end{tabular}

\begin{tabular}{|l|l|}
\hline 2015 & 2.377 .226 \\
\hline 2016 & 2.512 .005 \\
\hline 2017 & 2.658 .055 \\
\hline
\end{tabular}

Sumber : Data Olahan Peneliti, 2018.

Tabel di atas menunjukkan adanya peningkatan wisatawan mancanegara setiap tahunnya dari tahun 2010 hingga 2017. Familiarization Trip sendiri diadakan mulai dari tahun 2010, sehingga peneliti menyimpulkan bahwa pelaksanaan Program Famtrip berperan dalam memberikan peningkatan jumlah kunjungan wisatawan mancanegara ke Jakarta.

Sementara untuk kunjungan wisatawan asing ke Museum Tekstil di tahun 2017 juga mengalami peningkatan sebanyak $0,91 \%$ dari 44,357 pada tahun 2016 menjadi 44,761. Dari data tersebut, peneliti juga menyimpulkan bahwa Program Famtrip 2017 berperan dalam memberikan peningkatan jumlah kunjungan wisatawan mancanegara ke Jakarta.

\subsection{Hambatan Penelitian}

Setelah memahami kegiatan Familiarization Trip ini, maka dapat disimpulkan bahwa keberhasilan Famtrip banyak dipengaruhi oleh halhal ini baik yang bisa terkontrol maupun tidak bisa di kontrol. Berdasarkan wawancara dengan Ibnu, sebagai finalis Abang dan None DKI Jakarta yang berperan sebagai narasumber pada penelitian ini mengungkapkan tanggapannya terhadap Familiariatrion Trip. Selama menjabat sebagai Abang dan None DKI Jakarta 2017, Ibnu merupakan Abang dengan penugasan Familiarization Trip terbanyak yaitu 4 kali, yakni Singapura, Palestina, Yordania, dan Aljazair. Karena pengalamannya inilah maka Ibnu dipercaya untuk menjadi salah satu narasumber didalam penelitian ini. Selain itu, opini dari narasumber eksternal ini juga dapat digunakan untuk mengetahui hambatan secara objektif dari pihak luar Dinas Pariwisata dan Kebudayaan DKI Jakarta.

Ibnu menceritakan salah satu pengalaman yang dijumpai saat bertugas untuk menemani peserta Famtrip dari Yordania:

"Saat famtrip dari Yordania, Dia ini tidak hanya datang ke Jakarta, tapi ada Bali, Lombok, Bandung, dan Jakarta. Selama di Bali dan di Lombok, mereka tidak mendapatkan service yang baik dan perjalanan yang baik. Sangat singkat, terlalu buru-buru, tidak mendapatkan 
apa- apa, tiba-tiba udah pindah ke lain tempat, itu yang di luar Jakarta. Hanya Bandung yang membuat mereka merasa nyaman karena mereka bilang hotelnya bagus. Begitu sampai di Jakarta, mereka sudah membawa efek dari kota sebelumnya yang kesel. Sampai di Jakarta mereka di bawa ke hotel yang biasanya digunakan dalam setiap Famtrip untuk turis yang lain yang sama-sama beragama Muslim. Ternyata, service dari Hotelnya ga baik, dalam hal kebersihan. Alhasil, orang-orang yang diundang tersebut, tidak hanya jurnalis, tapi juga influencer kelas atas, terjadi complain yang begitu besar,mereka minta pindah hotel hanya karena atap ada kuning-kuning di loteng dan handuk ada sedikit bitnik-bintik. Mereka minta keluar hotel semua, artinya gini mereka sampai bilang ke kita ini adalah sesuatu yang disrespectful, kalau kita mau mengundang mereka, seharusnya kita bisa memberikan sesuatu yang memang betul-betul baik untuk mereka. Kalau begitu caranya, mereka mending balik ke rumah terus nulis Indonesia dan Jakarta is terrible. Jadi ga bagus dong begitu" (Azhar, wawancara data primer, 30 Juni 2018).

Salah satu pengalaman Ibnu ini menjadi salah satu pengalaman yang tidak mengenakan, dimana apa yang sudah disipakan oleh Seksi Promosi Luar Negeri Dinas Pariwisata dan Kebudayaan DKI Jakarta tidak sesuai dengan ekspektasi yang dimiliki oleh para peserta Famtrip sehingga terjadi complain dari peserta Famtrip itu sendiri.

Di dalam cerita Ibnu di atas dikatakan bahwa Dinas Pariwisata dan Kebudayaan DKI Jakarta menyediakan hotel yang memang biasa digunakan dalam setiap Famtrip untuk turis lain yang sama-sama beragama Muslims, namun ternyata para peserta Famtrip kali ini ialah influencer kelas atas sehingga terjadi complain yang begitu besar disebabkan oleh service hotel yang tidak memenuhi ekspektasi peserta Famtrip, yaitu atap ada kuning- kuning di atas loteng dan ada bintik-bintik di handuk.

Bisa dilihat bahwa Dinas di sini membawa peserta ke hotel yang biasa digunakan oleh setiap peserta Famtrip yang beragama Muslim, hal ini menunjukkan bahwa Dinas hanya memberikan tempat yang sama, untuk setiap kali Famtrip bagi tamu beragama Muslim, padahal perlu dibutuhkan lagi research yang mendalam mengenai latar belakang mereka. Dalam kasus ini, latar belakang peserta Famtrip adalah influencer highclass.
Menurut tamu famtrip dalam penjelasan Ibnu, saat kita mengundang tamu atau peserta untuk meliput tentang obyek-obyek wisata yang ada diJakarta, harusnya diperlihatkan yang memang betul-betul layak untuk dipublikasikan. Namun kendala yang memang dihadapi selanjutnya adalah budget.

Dalam kasus ini, tentu saja Dinas Pariwisata harus menyiapkan hotel yang lebih layak untuk peserta Famtrip yang memang high class. Menurut Ibnu, budget memang menjadi kendala, tapi ini soal mengangkat nama Jakarta itu sendiri,

"Memang budgetnya jadi lebih tinggi, tapi lagi-lagi ini soal 'pamer' yang harus ngangkat nama dari Jakarta itu sendiri" (Azhar, wawancara data primer, 30 Juni2018).

Permasalahan untuk melakukan research mendalam mengenai kebutuhan dari para peserta Famtrip juga dirasakan perlu adanya perubahan menurut Olivia selaku jurnalis yang pernah menjadi peserta Famtrip. Dirinya megatakan bahwa pembacanya tidak tertarik untuk membaca obyek wisata yang dia kunjungi, oleh karena itu Dinas perlu melakukan riset mengenai target audience dari media yang dimiliki oleh peserta Famtrip.

Selain itu juga memang perlu ada yang diperbaiki dari segi schedule- nya, Jakarta memang memiliki banyak obyek wisata yang beragam yang ingin ditunjukkan kepada tamu Famtrip, namun, banyaknya destinasi tersebut menjadikan tamu berpindah-pindah terlalu cepat dari satu tempat ke tempat yang lain dan belum merasakan dan mendapatkan apa yang mereka cari di tempat wisata tersebut. Ditambah dengan lalu lintas di Ibu Kota yang padat menjadikan waktu yang dibutuhkan untuk menuju satu tempat ke tempat lainnya semakin lama. Selain itu, jalanan yang kurang indah juga menjadi hambatan dalam kegiatan ini, karena itu akan menjadi hal yang kurang nyaman untuk dilihat dan dilalui.

Sedangkan menurut Sherly Yuliana, dalam menjual Jakarta perlu juga barang bagus untuk dijual sedangkan Jakarta masih memiliki kekurangan dalam menawarkan destinasi dan atraksi.

Hambatan yang telah dijabarkan di atas juga dibenarkan oleh Olivia Lim, selaku peserta Famtrip dari Singapura, ia mengatakan bahwa salahsatu yang perlu diperbaiki dari Jakarta adalah infrastructure dan transportasi agar dapat 
Jurnal Teknologi Informasi dan Komunikasi, ISSN : 2087-0868, Volume 11, Nomor 2, September 2020 , FAMILIRISATION TRIP OLEH DINAS PARIWISATA DAN KEBUDAYAAN DKI JAKARTA DALAM PENGENALAN MUSEUM TEKSTIK TERHADAP WISATA MANCANEGARA

memudahkan turis untuk mengunjungi tempat wisata. Selain itu juga perlu adanya instruksi dari bahasa Inggris. Olivia merupakan turis yang tidak mendapatkan pengalaman karena Olivia mengaku bahwa dirinya hanya ingin kembali ke Jakarta jika dirinya memiliki alasan yang kuat.

What do you think about Jakarta as a capital city?

It's busy, chaotic but dynamic and vibrant. It's progressing with the times but retains a lot of its heritage and traditions.

What do you think about Jakarta as a tourism destination?

I think there's a lot of potential - lots of hidden gems that are waiting to be discovered.

What to improve in Jakarta as a capital city?

Transport infrastructure, definitely!

What to improve in Jakarta as a tourism destination?

Make it easier for tourists to get around - but this is only possible if transport infrastructure is improved. Have more signs and instructions in English. Also need more young ambassadors (like yourself) to promote it better among young travellers in south-east Asia using social media lure them away from Bangkok and Hong Kong!

- What is your favorite destination and why?

Bangkok. It's just as chaotic and dynamic, but there is the very convenient skytrain and subway, cafes and restaurants with very cool and/quirky designs, good food from street food to fine dining, excellent shopping again from cheap to quality Thai design. But its tourism indu much more established, and there are many websites/bloggers who have written lots of articles about Bangkok and it's easy to find information.

Do you want to visit Jakarta again for holiday purpose?

Maybe, not sure yet. If there is a strong enough reason for me to return

Gambar 1. Hasil Wawancara dengan Olivia, dari Data Olahan Peneliti, 2018

Selain itu, sebagai Abang dan None yang ditugaskan untuk Familiarization Trip, Abang None memiliki fungsi yang besar karena Abang dan None merupakan orang-orang terpilih yang memiliki kemampuan lebih jauh dalam hal guiding dan knowledge. Selain mempromosikan, Abang dan None juga harus membantu pemerintah untuk mempromosikan dan mengangkat nama Jakarta. Lebih dari pada itu, Abang dan None harus bisa memberikan experience yang baik kepada tamu Famtrip. Saat terjadi permasalahn yang tidak bisa dihandle oleh Dinas, Abang None seharusnya bisa maintain good relations dengan mengadakan pembicaraan yang tepat. Sehingga tamu Famtrip bisa menganggap Abang dan None sebagai partner untuk mendapatkan informasi terkait Jakarta secara detail. BahkanAbangdan None harus bisa meyakinkan mereka sehingga bisa menjadi responden dan informan saat tamu Famtrip kekurangan informasi.

Seperti kita ketahui di atas bahwa dalam melaksanakan kegiatan Familiarization Trip, bahwa Abang None memiliki peran yang penting dalam menentukan keberhasilan Famtrip dengan cara memberikan experience yang lebih baik kepada para Tamu Famtrip dan juga maintain a good relations dengan mereka. Namun dalam pelaksanaannya, hal ini juga sering kali menjadi hambatan di mana Abang dan None yang terpilih untuk bertugas merupakan Abang None pasif yang tidak pro-aktif, sehingga mereka cenderunguntuk lebih diam dan go with the flow, sehingga Abang
None tidak bisa berfungsi seperti yang diharapkanseperti yang dikatakan oleh Ibnu

"Nambahin lagi, disini abang none penting untuk proaktif, kalau seandainya yang ditugaskan bukan abang none yang diem aja bukan pro-aktif, mereka akan diemaja, follow, kalau merekanya tidak proaktif, sayang. Disitulah menurut saya Abang None should have the bigger role buat keberhasilan" (Azhar, wawancara data primer, 30 Juni2018).

Begitulah hambatan yang dirasakan Ibnu dalam melaksanakan Familiarization Trip, (1) apa yang disediakan terkadang tidak memenuhi ekspektasi apa yang dibutuhkan, (2) terkadang terlalu banyak tempat yang ingin dikunjungi sehingga tamu tidak bisa merasakan experience, (3) keadaan lalu lintas di Jakarta itu sendiri yaitu macet, (4) jalanan di Jakarta yang rusak juga menjadi hambatan. Selain dalam segi research, mapping danpersiapan, (5) atraksi dan destinasi yang kurang hambtan juga terkadang terjadi saat pelaksanaannya, disebabkan karena (6) orang-orang yang tidak berfungsi dengan baik dalam pelaksanaannya. Inilah sekiranya hambatan yang ditemukan di dalam pelaksanaan Famtrip.

\section{Cara Pengajuan dan Pengutipan}

Dari pembahasan diatas tentang strategi Familirization Trip oleh oleh Dinas Pariwisata dan Kebudayaan DKI Jakarta Dalam Pengenalan Museum Tekstil terhadap Wisatawan Mancanegara, peneliti menarik kesimpulan sebagai berikut:

1. Kampanye Famtrip telah dilaksanakan dengan baik seperti sebagaimana seharusnya. Dinas Pariwisata dan Kebudayaan DKI Jakarta berhasil menggaet jurnalis maupun tour operator dari dalam negeri untuk mengunjungi objek-objek wisata yang ada di Jakarta, baik dilaksanakan seluruhnya oleh Dinas Pariwisata dan Kebudayaan DKI Jakarta maupun atas permintaan Kemenpar. Dinas Pariwisata dan Kebudayaan DKI Jakarta telah berhasil melakukan strategi public relations delapan langkah. Yang pertama yaitu situation dimana Dinas Pariwisata dan Kebudayaan DKI Jakarta melakukan analisa terhadap negara mana yang akan diundang untuk menjadi peserta Famtrip dan apa latar belakang dari kebudayaan peserta famtrip dan latar belakang peserta famtrip itu sendiri. Kedua, objectives, dengan memiliki tujuan dalam pelaksanaan famtrip itu sendiri yaitu adanya peningkatan wawasan mengenai objek-objek wisata Jakarta maupun museum tekstil, 
peningkatan publikasi Jakarta maupun museum tekstil sebagai Kota Pariwisata, serta peningkatan jumlah wisatawan asal negara peserta Famtrip ke Jakarta maupun ke Museum Tekstil. Audience yang dipilih berdasarkan laporan kunjungan wisatawan mancanegara hasil tahun sebelumnya. Akan dipilih beberapa negara dengan tujuan untuk meningkatkan semakin banyak kunjungan dari negara tersebur. Sedangkan untuk peserta Famtrip, akan dipilih oleh KBRI atau KJRI. Strategy yang dilakukan oleh Dinas Pariwisata dan Kebudayaan DKI Jakarta adalah melalui Famtrip dimana peserta famtrip yang diundang ke Jakarta akan memiliki pengalmaan langsung mengunjungi objek wisata yang ada di Jakarta dengan harapan mereka akan mempublikasikan cerita ini untuk meningkatkan kunjungan wisatawan mancanegara. Tactics yang dilaksanakan adalah menyediakan guide yang menguasai bahasa asing dan menguasai sejarah perkembangan Kota Jakarta dan memiliki wawasan luas agar informasi bisa disampaikan secara efektif. Selain itu juga mebuat jadwal kunjugan, menyediakan tiket pesawat, membuat dokumentasi, membayar biaya kunjungan, dan menyediakan akomodasi dan transportasi hingga seluruh biaya yang dikeluarkan selama kegiatan berlangsung. Setiap pelaksanaan akan didampingi oleh petugas pendamping untuk menjaga agar kegiatan berjalan sesuai dengan yang sudah direncanakan. Timetable pelaksanaan kampanya Famtrip tahun 2017 dilaksanakan dimulai Bulan Maret sampai dengan Bulan November 2017 sedangkan perencanaan dimulai sebelumnya danlaporandilakukan setelahnya, Budget yang dibutuhkan untuk melaksanakan kampanye ini menggunakan dana dari pemberdayaan famtrip yang menghabiskan dana sekitar 2 Miliar setiap tahunnya dengan menghabiskan 100-200 juta dalam sekali kegiatan tergantung dari jumlah peserta, lama kunjungan, dan destinasi yang dikunjungi. Evaluation dari Dinas Pariwisata dan DKI Jakarta adalah memastikan bahwa setiap peserta famtrip melakukan tugasnya, bila jurnalis, menghasilkan sebuah publikasi di media. Dinas Pariwisata juga membuat laporan kegiatan dan Laporan publikasi sebagai bahan evaluasi.

2. Peneliti juga melakukan penelitian mengenai dampak dari pelaksanaan Famtrip dalam memperkenalkan Museum Tekstil dan menemukan hasil publikasi yang dibuat oleh para peserta Famtrip sehingga memang pelaksanaan Famtrip memiliki dampak dalam memperkenalkan Museum Tekstil kepada wisatawan mancanegara namun emang tidak bisa diketahui seberapa efektif Famtrip dalam memperkenalkan Museum Tekstil kepada wisatawan mancanegara karena memang banyak kegiatan yang dilakukan untuk mempromosikan Museum Tekstil kepada wisatawan mancanegara dan promosi yang dilakukan oleh Museum Tekstil sendiri.

3. Namun dalam Pelaksanaannya, famtrip memiliki beberapa kendala, Famtrip dilakukan dalam waktu lebih dari satu hari, maka dari itu peserta Famtrip akan berkunjung ke banyak destinasi atau acara yang ada di Jakarta. Jurnalis idak bisa mereview semua komponen mulai dari hotel, tempat makan, seluruh objek wisata, dan seluruh objek kegiatan. Sehingga tidak bisa dipastikan bahwa jurnalis yang berkunjung ke Museum Tekstil akan selalu menghasilkan publikasi tentang Museum Tekstil. Karena kembali lagi hal itu sesuai dengan latar belakang journalis dan pengalaman yang mereka dapatkan selama disini. Selain itu, hambatan lain ialah persiapan yang dilakukan oleh Dinas tidak menemui ekspektasi peserta Famtrip, Infratstruktur dan lalu lintas di Jakarta yang tidak mendukung, kurangnya destinasi dan atraksi yang dimiliki, peran dan fungsi para pendukung acara Famtrip yang tidak sesuai dengan yang diharapkan. Hambatan lain ialah, faktor keberhasilan Famtrip dalam meningkatkan kunjungan wistawan mancanegara juga tidak bisa dinilai atau di kontrol. Terbukti bahwa jumlah wisatawan mancanegara yang mengunjungi Jakarta dan Museum Tekstil bertambah, namun kunjungan tersebut tidak sema- mata hanya dihasilkan dari Famtripsaja.

Upaya yang bisa dilakukan oleh Famtrip untuk menjaga agar setiap peserta famtrip melakukan tanggung jawabnya adalah memastikan ke KBRI dan KJRI untuk melaporkan hasil publikasi yang diterbitkan oleh peserta famtrip untuk menjadi bukti dari peserta famtrip itu sendiri. Juga diperlukan research mendalam sehingga bisa menyusun perencanaan dengan baik dan memastikan bahwa acara berjalan dengan lancar.

\section{Daftar Pustaka:}

Ardianto, E. (2014). Metode Penelitian Untuk Public Relations. Simbiosa Rekatama Media. 
Jurnal Teknologi Informasi dan Komunikasi, ISSN : 2087-0868, Volume 11, Nomor 2, September 2020 , FAMILIRISATION TRIP OLEH DINAS PARIWISATA DAN KEBUDAYAAN DKI JAKARTA DALAM PENGENALAN MUSEUM TEKSTIK TERHADAP WISATA MANCANEGARA

Babo, J. P. (2016). Peranan Dinas Pariwisata dan Ekoknomi Kreatif Dalam Mengelola Wisata Pantai Kabupaten Banggai Laut. Jurnal Eksekutif, 1(7).

Butterick, K. (2014). Pengantar Public Relations Teori dan Praktik. PT. Raja Grafindo Persada.

Effendy, O. . (2009). Human Relations \& Public Relations. Mandar Maju.

Jakarta Tourism. (2015). Jakarta Tourism. http://jakartatourism.go.id/2015/generalinformation?language $=\mathrm{id}$

Kriyantono, R. (2006). Teknik Praktis Riset Komunikasi. Kencana Prenada Media Group.

Kurniardi. (2015). Kempar Gencarkan "Fam Trip." http://www.beritasatu.com/destinasi/32 2815-kempar-gencarkan-fam- trip.html

Lexy J. Moleong, D. M. A. (2019). Metodologi Penelitian Kualitatif (Edisi Revisi). PT. Remaja Rosda Karya. https://doi.org/10.1016/j.carbpol.2013. $\underline{02.055}$

Museum Tekstil Jakarta. (2013). No Title.

Prakoso, J. (2017). Fam Trip Strategi Kemenpar Untuk Promosi Wisata Indonesia. Traveldetik.Com.

Ruslan, R. (2008). Kiat dan Strategi Kampanye Public Relation. Raja Grafindo Persada. 